\title{
Death notification: a digital communication platform for simulated patient-based training with medical students
}

\author{
Mary Hughes, ${ }^{1,2}$ Brett Gerstner, ${ }^{2}$ Anna Bona, ${ }^{1}$ Lauren Falvo, ${ }^{1}$ Cherri Hobgood, ${ }^{1}$ \\ Rami A Ahmed (10) 1
}

- Supplemental material is published online only. To view please visit the journal online (http://dx.doi.org/10.1136/ bmjstel-2020-000653).

${ }^{1}$ Division of Simulation, Emergency Medicine, Indiana University School of Medicine, Indianapolis, Indiana, USA 2Department of Osteopathic Medical Specialties, Michigan State University College of Osteopathic Medicine, East Lansing, Michigan, USA

\section{Correspondence to}

Rami A Ahmed, Department of Emergency Medicine, Indiana University School of Medicine, 720 Eskenazi Avenue | FT 3, Indianapolis, IN 46202, USA

raaahmed@iu.edu

Received 22 May 2020 Revised 24 July 2020

Accepted 8 September 2020

Check for updates

(c) Author(s) (or their employer(s)) 2020. No commercial re-use. See rights and permissions. Published by BMJ.

To cite: Hughes $M$, Gerstner B, Bona A, et al. BMJ Simul Technol Enhanc Learn Epub ahead of print: [please include Day Month Year]. doi:10.1136/bmjstel2020-000653

\section{INTRODUCTION}

Medical simulation experiences, focused on enhancing essential communication skills, provide high value to trainees. These communication-based simulations often require little equipment and instead use trained faculty facilitators who can impart clinical significance and expertise to trainees. Teaching communication skills and techniques remotely is theoretically possible but has been largely unexplored in medical education. ${ }^{1}$ The COVID-19 pandemic and the subsequent restrictions imposed by shelter-inplace orders and social distancing created a need to expand traditional training methods and experiment with remote simulation training for communication skills. In this brief report, we explore the experience, outcomes and barriers to implementing a simulated communication skill curriculum focused on death notification to a cohort of remote medical students.

\section{PROBLEM ADDRESSED}

A 'readiness for residency, simulation-based competency assessment' 2 -week elective class was scheduled as a capstone experience for fourth-year Michigan State University College of Osteopathic Medicine (MSUCOM) students during their final month of training ( $\mathrm{n}=12$ students). One week prior to course initiation, Michigan State University mandatedall coursework be conducted on a digital communication platform (Zoom $\left.{ }^{\circledR}\right)$ due to 'shelter-in-place' and social distancing orders designed to quell the COVID-19 pandemic. Faculty co-directors $(\mathrm{MH}$, BG) were faced with a complete course redesign for a simulation heavy curriculum, requiring significant in-person instruction. Some content was not adaptable to format revisions; however, other curricular elements were amenable to a pedagogy change that allowed students to observe shelter-in-place restrictions. One such activity was a death notification training module using the GRIEV_ING mnemonic. ${ }^{2}$

\section{WHAT WAS TRIED}

We modified a well-designed previously studied live simulation programme, the GRIEV_ING educational method, which has been demonstrated to improve death notification skills in emergency medicine interns and paramedics to a digital communication platform. ${ }^{3}$ All content was identical to the in-person version; however, learners were remote; separated by hundreds of miles from the simulated patients (SPs), faculty and lecturer. Zoom and email were used to schedule students with the SPs, create the 'door note' introducing the student to the patient and the scenario, and record the interactions. For both the in-person and digital communication platform teaching of the module, the educational content session was preceded by a written knowledge pretest, a self-efficacy survey and an individual performance assessment with an SP to deliver a death notification. This preassessment of knowledge, self-efficacy and skill was followed by a 1-hour content lecture on how to use the GRIEV ING mnemonic to deliver a more effective death notification. Students were encouraged to interact with SPs with questions and answers. Following the lecture, groups of students were trained to use the GRIEV_ING method using a 1-hour rapid cycle deliberate practice session (see figure 1). In this session, students interacted with an SP to deliver the death notification while their performance was coached by simulation faculty $(n=4)$ using the rapid cycle debrief method. ${ }^{4}$ This session was immediately followed by a post-assessment in which the individual student delivered a death notification to another SP. The training ended with a written post-test and the self-efficacy survey. Pretest and post-test, cases, door notes, faculty and SPs participated in both the in-person and the digital communication platform process, and the timing was kept identical. The participating faculty all completed a 3-hour rapid cycle deliberate practice training session. The SPs completed their standard 2-hour training session of the case and separate 1-hour rehearsal prior to the execution of the event. (for cases, see online appendix 1). These assessments and data were delivered, collected and maintained, via the D21 learning management system in use at MSUCOM. All study data were anonymised, and the study was declared 'not human subjects research' by the Michigan State University Human Research Protection Program of the Institutional Review Board, study \# 4203.

\section{WHAT LESSONS WERE LEARNED}

The student feedback regarding this curriculum was overall positive. Students enjoyed the expert content and small-group classroom feel provided by all aspects of the curriculum. The learners also appreciated the opportunity to practise this difficult communication with trained SPs, which provided realism during the scenarios.

Fully relying on technology to complete the curriculum did present some challenges. There is significantly more organisational set-up required to implement each 

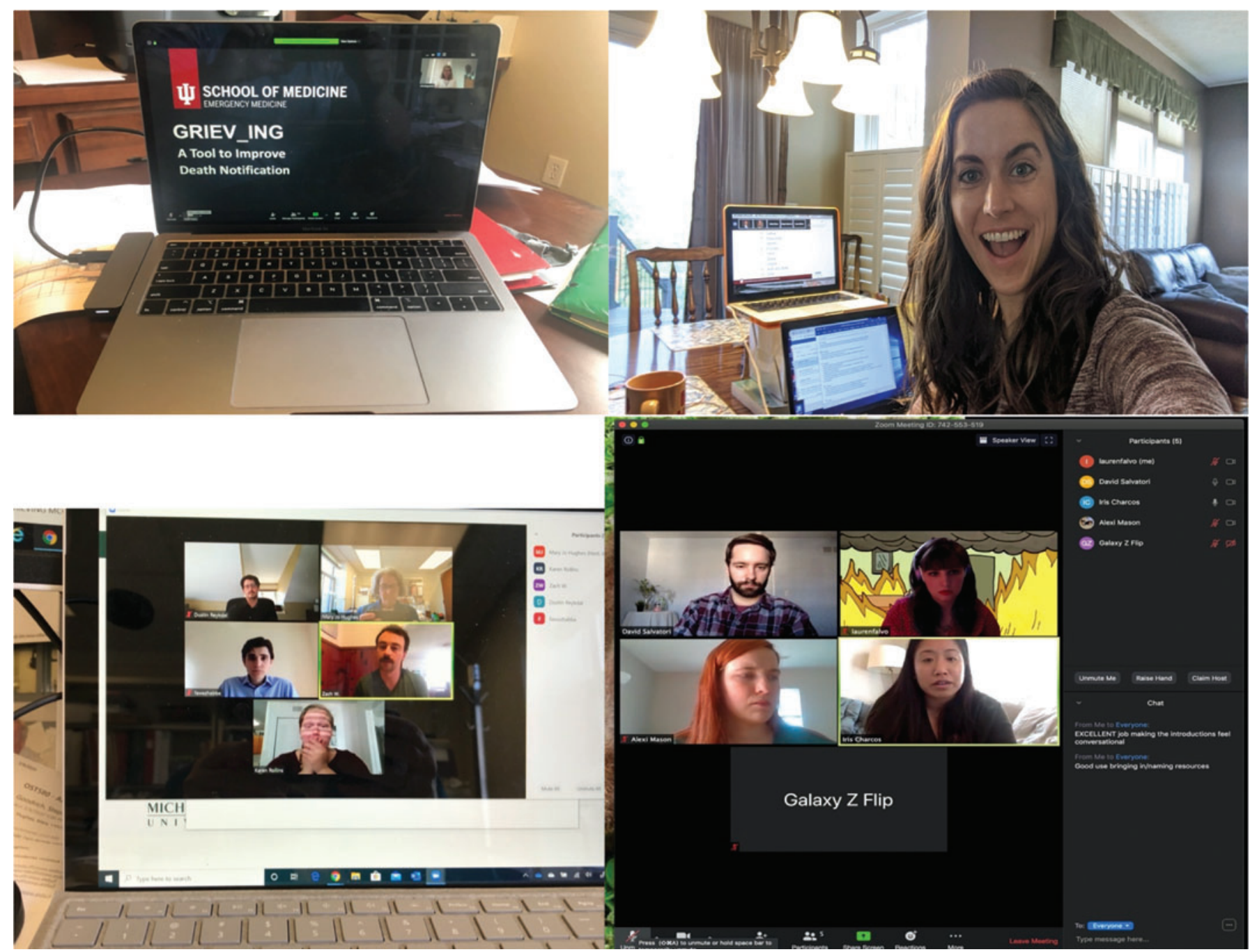

Figure 1 Death notification training via Zoom demonstrating two phases of the study.

of the Zoom interactions, as trainees, SPs and faculty must be invited to the Zoom meeting. In addition to set-up for the separate Zoom meetings timed, emails were used in place of door notes to deliver content in a just in time manner immediately before their entry into the SP's Zoom room. Once the trainee entered the room, the SP was required to record it for later review, and this process was repeated for each of the sessions. Much of this administrative burden can be shifted to non-faculty members in future iterations; however, in this brief trial faculty completed this activity. Additionally, we noted that the ability to effectively pre-brief students was limited, as most of the instructions were provided through word documents which did not allow the opportunity to clarify nuances of the curriculum and order of the events. In the future, this will be adjusted by adding clarifying statements to the introduction documents, and potentially expanding the initial Zoom meeting to provide a detailed prebrief and use the waiting room feature for door notes.

The inability to touch the SP, which is a powerful tool, particularly in osteopathic medicine, was noted to be absent, and this impacted the ability of faculty to both model and evaluate physical behaviours such as empathic gestures and posture.

\section{CONCLUSION}

We have demonstrated that a digital communication platform can be used to effectively deliver difficult communication content such as death notification. This material was taught within the same time and with similar outcomes as the inperson experience held in a simulation laboratory. This digital communication platform model has the potential to demonstrate considerable cost savings by using platforms such as Zoom and mitigating the need for rental of the simulation laboratory. Faculty should feel confident that remote communication simulations can be implemented effectively without loss of student engagement and skill acquisition.

\section{Twitter Rami Ahmed @RamiAhmedDO.}

Acknowledgements The authors thank Mrs Karen Schroedle, BA, CHSE, simulated patient educator, for her tireless efforts in the training of outstanding simulated patients and for her efforts in facilitating the execution of this project on short notice.

Contributors $\mathrm{MH}$ and $\mathrm{BG}$ were instrumental in the logistics, set-up and execution of this study. $M H, B G, A B, L F, C H$ and RAA contributed as faculty during the training and to the analysis and interpretation of the data for the work, composition and editing of the article, approval of the final article for publication, and agree to be accountable for all aspects of the work in ensuring that questions related to any part of the work are appropriately investigated and resolved.

Funding This research received no specific grant from any funding agency in the public, commercial or not-for-profit sectors.

Competing interests None declared.

Provenance and peer review Not commissioned; externally peer reviewed. Data availability statement Data are available upon reasonable request. 
Supplemental material This content has been supplied by the author(s). It has not been vetted by BMJ Publishing Group Limited (BMJ) and may not have been peerreviewed. Any opinions or recommendations discussed are solely those of the author(s) and are not endorsed by BMJ. BMJ disclaims all liability and responsibility arising from any reliance placed on the content. Where the content includes any translated material, BMJ does not warrant the accuracy and reliability of the translations (including but not limited to local regulations, clinical guidelines, terminology, drug names and drug dosages), and is not responsible for any error and/ or omissions arising from translation and adaptation or otherwise.

This article is made freely available for use in accordance with BMJ's website terms and conditions for the duration of the COVID-19 pandemic or until otherwise determined by BMJ. You may use, download and print the article for any lawful, noncommercial purpose (including text and data mining) provided that all copyright notices and trade marks are retained.

\section{ORCID ID}

Rami A Ahmed http://orcid.org/0000-0001-8518-6083

\section{REFERENCES}

1 van Galen LS, Wang C, Nanayakkara P, et al. Telehealth requires expansion of physicians' communication competencies training. Med Teach 2019;41:714-5.

2 Hobgood C, Harward D, Newton K, et al. The educational intervention 'GRIEV_ING' improves the death notification skills of residents. Acad Emerg Med 2005;12:296-301.

3 Ahmed RA, Weaver L, Falvo L, et al. Rapid cycle deliberate practice: death notification. Clin Teacher 2020. In Press.

4 Hunt EA, Duval-Arnould JM, Nelson-McMillan KL, et al. Pediatric resident resuscitation skills improve after 'rapid cycle deliberate practice' training. Resuscitation 2014;85:945-51. 